\title{
Thr1313Met Mutation in Skeletal Muscle Sodium Channels in a Japanese Family with Paramyotonia Congenita
}

\author{
Masanobu KinOSHITA, Ryogen SASAKI*, Tadasuke NAgAnO, Akihiko MatsudA, \\ Satoko NAKAmura, Misato TAKAhama, Manabu OHnUKI, Hajime HaSEgAwA, \\ Tetsuya MitARAI and Kazuhiko HIROSE**
}

\begin{abstract}
A 37-year-old Japanese woman was referred from another clinic to confirm the diagnosis of myotonia congenita. She had experienced cold-induced myotonia and muscle stiffness from early childhood. Of her three children, her elder son and her daughter have clinical features similar to hers. They experience neither grip nor percussion myotonia during warm weather, whereas myotonia is provoked by cold. Her younger son has no symptoms. DNA analyses of the SCN4A gene showed a C to $T$ transition at nucleotide position 3938 in exon 22 of SCN4A (Thr1313Met) in all three affected family members, but not in the unaffected son. Paramyotonia congenita, the prevalence of which is very low in Japan, was diagnosed based on their clinical features and DNA analysis results.

(Internal Medicine 42: 856-861, 2003)
\end{abstract}

Key words: paramyotonia congenita, SCN4A gene, missense mutation

\section{Introduction}

Paramyotonia congenita (PMC) is an autosomal dominant muscle disease characterized by paradoxical myotonia, defined as increased muscle stiffness on repeated activity, as well as cold-induced muscle stiffness and weakness (1-8). Hyperkalemic periodic paralysis (Hyper PP), hypokalemic periodic paralysis (Hypo PP) type 2, potassium-aggravated myotonia (myotonia fluctuans, myotonia permanens, and acetazolamide-induced myotonia), and hyperkalemic paralysis and paramyotonia (formerly called paralysis periodica paramyotonia) also comprise a set of dominantly inherited muscular disorders (1-8). All of these conditions are caused by missense mutations in the adult skeletal muscle sodium channel $\alpha$-subunit (SCN4A) gene which encodes SCN4A and is located on chromosome 17q 23-25 (1-31). Moreover, myotonia occurs in myotonia congenita (Thomsen's disease, autosomal dominant and Becker's generalized myotonia, autosomal recessive) $(1-8,32,33)$. Both diseases are reported to be caused by missense mutations in the skeletal muscle chloride channel (CLCN1) gene located on chromosome $7 \mathrm{q} 35(1-8,32)$. This myotonia phenomenon which is associated with sodium and chloride channel disorders is difficult to distinguish clinically and electromyographically (EMG).

We examined members of a Japanese family in whom myotonia congenita had been diagnosed by another clinic's doctor. Because they suffered cold-induced myotonia, muscle stiffness, or both, we looked for abnormal mutations of the SCN4A gene. DNA analysis detected a Thr1313Met mutation in all three of the affected family members. The diagnosis was PMC.

For editorial comment, see p 769.

\section{Case Report}

A 37-year-old Japanese woman (I-1) was referred to us from another clinic to confirm the diagnosis of myotonia congenita (Fig. 1). Since the first decade of life, she had experienced muscle stiffness in her upper and lower extremities during exercise in the cold. In addition, paralytic attacks during exercise followed by muscle stiffness were provoked by exposure to cold, whereas they did not occur in warm surroundings. These clinical features were not initiated by eat-

From the Fourth Department of Internal Medicine, Saitama Medical Center, Saitama Medical School, Saitama, *Department of Neurology, Mie University School of Medicine, Mie and **Ueno Hospital Internal Medicine, Tokyo

Received for publication July 1, 2002; Accepted for publication March 26, 2003

Reprint requests should be addressed to Dr. Masanobu Kinoshita, the Fourth Department of Internal Medicine, Saitama Medical Center, Saitama Medical School, 1981 Kamoda-Tsujido, Kawagoe, Saitama 350-8550 
I

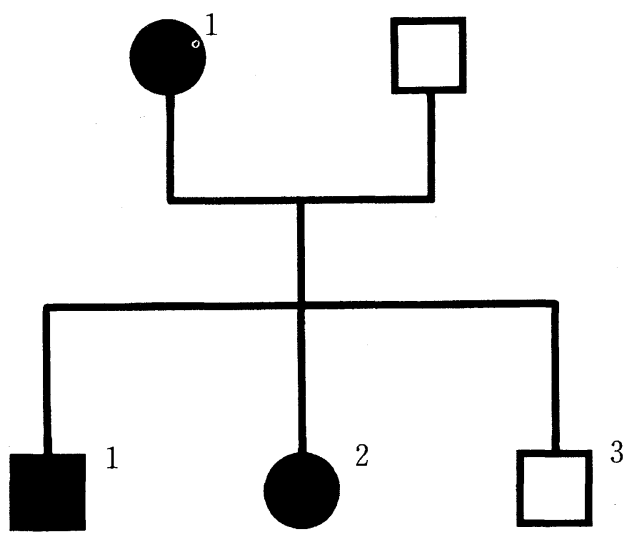

Figure 1. Pedigree of a Japanese family with paramyotonia congenita (PMC). The proband, her elder son, and her daughter all have PMC. Proband (I-1) and daughter (II-2) closed circles, elder son (II-1) closed square. Her younger son (II-3), open square, is unaffected.

ing too much fruit or other foods. She did not visit a hospital until her middle thirties because, except for cold-induced muscle stiffness, subjectively she had been free of muscle weakness. She had difficulty in opening her hands after riding her motorcycle in cold weather. Both her elder son (II-1) and her daughter (II-2) had similar clinical features from age 4 or 5 (Fig. 1), whereas her younger son (II-3) had none of these symptoms (Fig. 1).

She (I-1) has well developed skeletal muscles and a Herculean type of physique (Fig. 2). Her daughter (II-2) has a lean physique, whereas her elder son (II-1) has a physique similar to his mother's (I-1) (Fig. 2). During warm weather, they experience neither grip nor percussion myotonia, whereas both are provoked by cold water $\left(4^{\circ} \mathrm{C}\right)$. In addition, they have paradoxical myotonia. In contrast, the younger son (II-3) suffers neither cold-induced nor paradoxical myotonia. The grasping power of patients I- 1 and II- 2 was mildly or slightly reduced (I-1: rt 20.5 , lt $18.5 \mathrm{~kg}$, II-2: rt 20.0 , lt 22.0 $\mathrm{kg}$ ), whereas the power of patient II-1 was normal (rt 40.0, It $38.0 \mathrm{~kg}$ ). Distal muscle strength in all the extremities was slightly decreased in all 3 patients, whereas proximal muscle strength was nearly normal. No facial muscle weakness was detected.

Laboratory findings are shown in Table 1 . Serum creatine kinase $(\mathrm{CK})$ was slightly elevated in both patients I-1 (259 IU/l, normal range; <140) and II-1 (290 IU/l), but normal in patient II-2 (133 IU/l). Serum potassium was normal in all three (patient I-1 $4.1 \mathrm{mEq} / l$, patient II-1 $3.9 \mathrm{mEq} / l$, and patient II-2 $4.4 \mathrm{mEq} / \mathrm{l}$; normal range; 3.3-5.0), and other laboratory findings were all nearly normal. The EMG for patient I-1 detected myotonic runs in all her extremities (Fig. 3).

On the basis of these findings, we suspected that the diagnosis should be PMC rather than myotonia congenita (Thomsen's disease or Becker's generalized myotonia) (18,33 ), and informed consent for the molecular analyses of
I-1 II-1

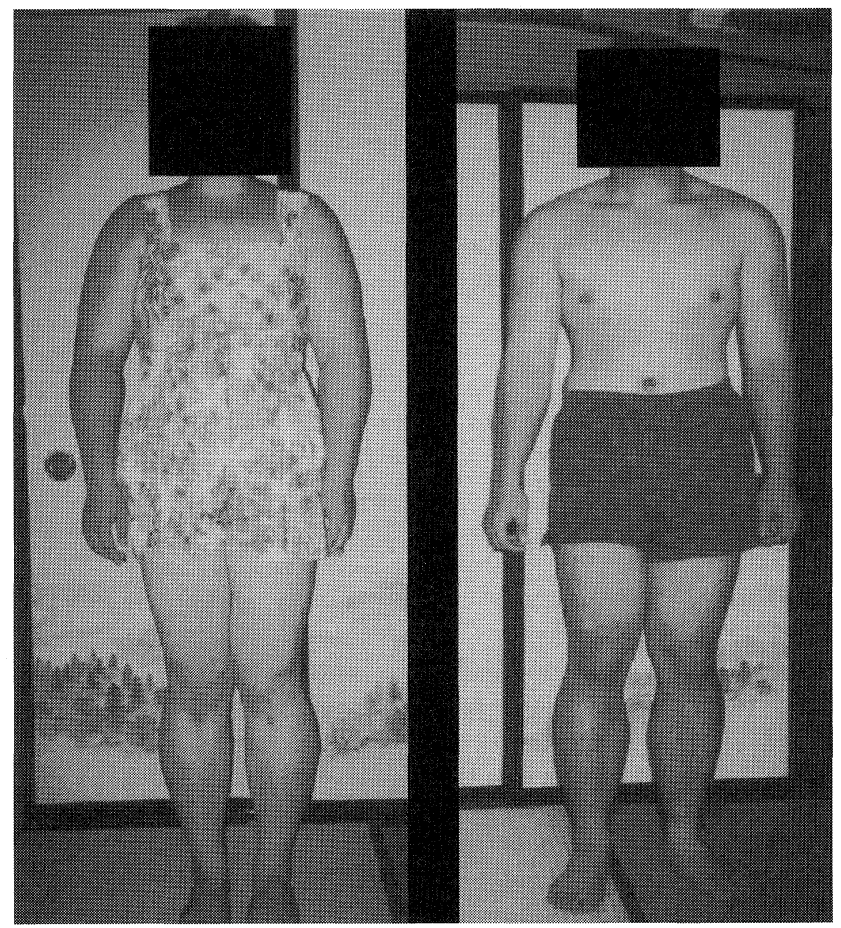

Figure 2. Physiques of patients I-1 (left) and II-1 (right). Both have well developed skeletal muscles without atrophy and Herculean type physiques.

their SCN4A genes was obtained from each family member. High molecular weight genomic DNA was extracted from peripheral blood leukocytes taken from each of them. Because the mutations that cause PMC are located in exons 22 and 24 of the SCN4A gene, as reported previously (123 ), we made mutation analyses of these exons. Each exon was amplified by a polymerase chain reaction (PCR), and purified fragments of the PCR products were sequenced by dideoxynucleotide chain termination in an automated DNA sequencer (ABI 310, Perkin Elmer, and USA). Direct nucleotide sequence analysis of the double-standard PCR products from the three affected patients (I-1, II-1, and II-2) showed a $\mathrm{C}$ to $\mathrm{T}$ transition at nucleotide position 3938 in exon 22 of the SCN4A gene, resulting in the substitution of threonine for methionine at amino acid position 1313 in SCN4A (Thr1313Met) (Fig. 4). All the sequences in that gene were examined, but no other mutations were detected (data not shown). In contrast, the products in the unaffected family member (II-3) showed no mutation in exon 22 of SCN4A (Fig. 4). PMC was the final diagnosis for the affected family members based on their clinical features and DNA analysis results.

The standard therapy for myotonia patients is administration of sodium channel blocking agents of the lidocaine type (34-36). Mexiletine is favored because it has less serious side effects than tocainide and lidocaine (34-36). Mexiletine 
KINOSHITA et al

Table 1. Laboratory Findings

\begin{tabular}{|c|c|c|c|c|c|c|c|}
\hline & $\mathrm{I}-1$ & II-1 & $\mathrm{II}-2$ & & $\mathrm{I}-1$ & II-1 & II-2 \\
\hline $\mathrm{CBC}$ & & & & Blood chemistry & & & \\
\hline WBC $\left(/ \mathrm{mm}^{3}\right)$ & 7,000 & 4,900 & 5,600 & Total protein $(\mathrm{g} / \mathrm{dl})$ & 7.7 & 7.2 & 7.9 \\
\hline $\mathrm{RBC}\left(\times 10^{4} / \mathrm{mm}^{3}\right)$ & 444 & 484 & 426 & AST (IU/l) & 21 & 14 & 17 \\
\hline $\mathrm{Hb}(\mathrm{g} / \mathrm{dl})$ & 13.8 & 15.1 & 12.8 & ALT (IU/l) & 24 & 12 & 12 \\
\hline $\mathrm{Ht}(\%)$ & 40.8 & 43.8 & 38.1 & LDH (IU/l) & 176 & 133 & 152 \\
\hline \multirow[t]{3}{*}{ Platelet $\left(\times 10^{4} / \mathrm{mm}^{3}\right)$} & 34.4 & 34.3 & 25.5 & $\mathrm{CK}(\mathrm{IU} / l)$ & 259 & 290 & 133 \\
\hline & & & & ALP (IU/l) & 219 & ND & ND \\
\hline & & & & LAP (IU/l) & 45 & ND & 54 \\
\hline Urinalysis & & & & $\gamma \mathrm{GT}(\mathrm{IU} / l)$ & 45 & 17 & 12 \\
\hline Specific gravity & 1.021 & 1.010 & 1.009 & BUN (mg/dl) & 12 & ND & ND \\
\hline $\mathrm{pH}$ & 6.0 & 6.5 & 6.5 & Creatinine (mg/dl) & 0.70 & 0.99 & 0.70 \\
\hline Protein & $(-)$ & $(-)$ & $(-)$ & $\mathrm{UA}(\mathrm{mg} / \mathrm{dl})$ & 6.3 & 6.0 & 4.4 \\
\hline Sugar & $(-)$ & $(-)$ & $(-)$ & $\mathrm{Na}(\mathrm{mEq} / \mathrm{l})$ & 140 & 141 & 139 \\
\hline Urobilinogen & $( \pm)$ & $( \pm)$ & $( \pm)$ & $\mathrm{K}(\mathrm{mEq} / l)$ & 4.1 & 3.9 & 4.4 \\
\hline Sediment & & & & $\mathrm{Cl}(\mathrm{mEq} / l)$ & 108 & 103 & 103 \\
\hline RBC (/HPF) & 1 & 1 & 1 & $\mathrm{Ca}(\mathrm{mg} / \mathrm{dl})$ & 9.6 & 10.0 & 10.1 \\
\hline \multirow[t]{2}{*}{ WBC (/HPF) } & 1 & 0 & 1 & $\mathrm{P}(\mathrm{mg} / \mathrm{dl})$ & ND & 3.3 & 4.3 \\
\hline & & & & CRP (mg/dl) & 0.2 & 0.0 & 0.0 \\
\hline
\end{tabular}

ND: not done.

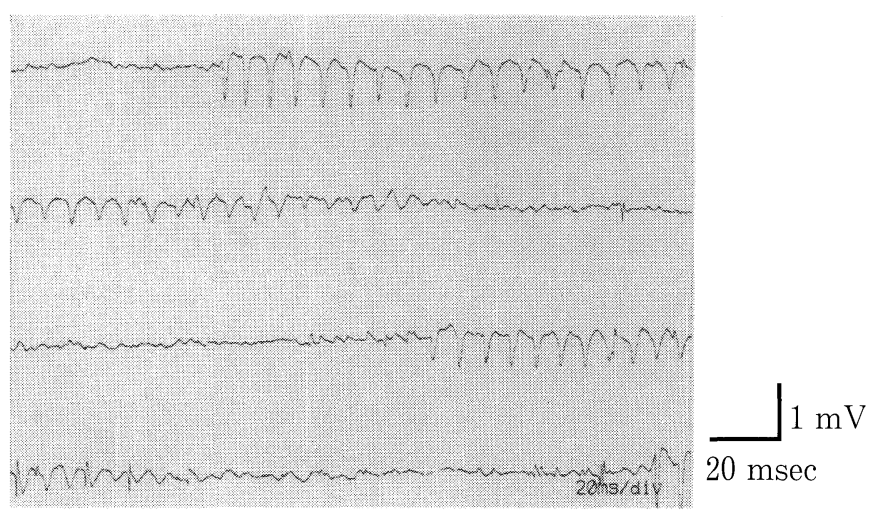

Figure 3. Electromyogram for I-1 patient. Myotonic discharges and runs are shown.

(300 mg), therefore, was administered orally two or three times daily to all three patients. All showed rapid disappearance of myotonia and muscle stiffness at cold temperatures.

\section{Discussion}

Three members of this family suffered cold-induced and paradoxical myotonia and/or cold-induced muscle stiffness. Both patients I- 1 and II- 2 had slightly decreased grasping power. Patients I- 1 and II- 1 have Herculean type physiques, a characteristic of Thomsen's disease $(1-8,33)$. Their medical histories show no evidence of Hyper PP or Hypo PP type 2. The genetic pattern is consistent with autosomal dominant inheritance. Their clinical features are closer to those of
PMC than myotonia congenita (Thomsen's disease). The CLCN1 gene located on chromosome 7q35 $(1-8,32)$, which is responsible for Thomsen's and Becker's myotonia congenita, first was analyzed. No abnormal mutation was found (data not shown). The clinical features of myotonia congenita and PMC are similar to those of potassiumaggravated myotonia (myotonia fluctuans, myotonia permanens, and acetazolamide-induced myotonia) $(1-8,27$, 29-31). In myotonia fluctuans and permanens, however, cold has no effect on the myotonia, and paralysis is not a feature $(1-8,29,30)$. In acetazolamide-induced myotonia, the myotonia phenomenon provoked by fasting and oral potassium is mildly enhanced only by cold. Like Hyper PP it is relieved by carbohydrates $(1-8,31)$. These clinical features of potassium-aggravated myotonia differ from those of our patients. We therefore looked for the presence of mutations in the SCN4A gene that are responsible for the sodium channelopathies as PMC, Hyper PP, Hypo PP type 2, and potassium-aggregated myotonia. The three affected family members (I-1, II-1, and II-2) had a C-to-T transition at nucleotide 3938 which causes the substitution of methionine for threonine at codon 1313 . The unaffected family member (II-3) did not have this transition. This mutation, present in the SCN4A gene of our three patients, has not been reported previously in potassium-aggravated myotonia $(1-8,27,29$ 31). On the basis of their clinical features and DNA analysis results, $\mathrm{PMC}$ was the final diagnosis.

Approximately 20 missense, SCN4A gene mutations have been identified in various types of sodium channelopathies (1-31). In our investigation, 11 missense mutations were found in the SCN4A gene in PMC (Fig. 5) (1-23). The Thr1313Met mutation in PMC, detected in our patients, has 
I-1 (affected)

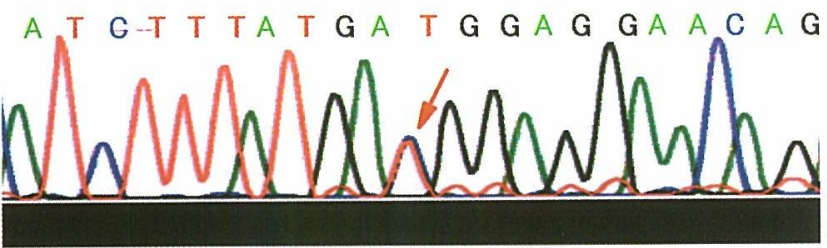

II-1 (affected)

A T G T T TA T G A T G G A G G A A C A G

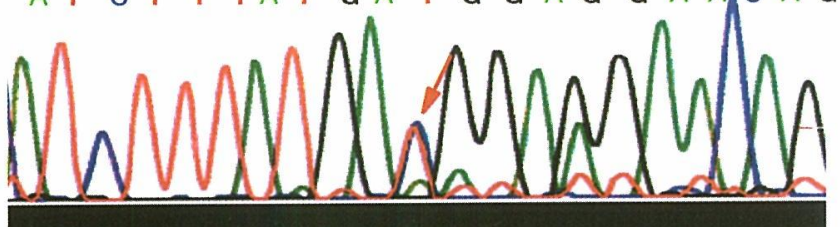

II-2 (affected)

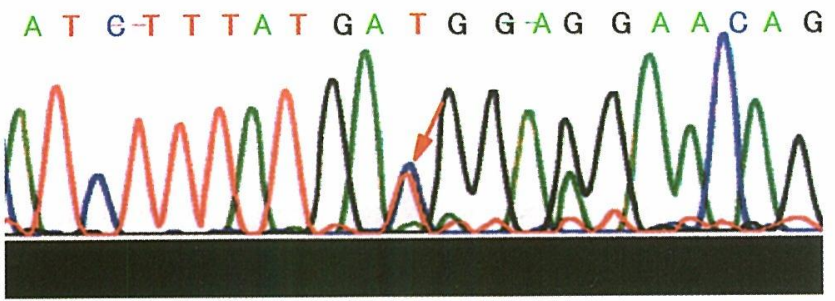

II-3 (unaffected)

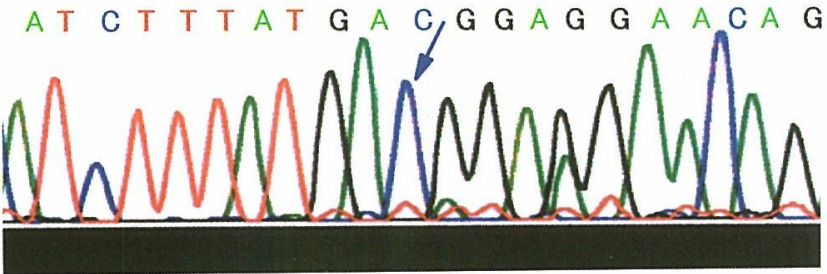

Figure 4. Sequence electropherograms for the family members (I-1: the proband, II-1:elder son, II - 2: daughter, II-3: younger son). The nucleotide at codon 3938 (arrow) is T in patients I-1, II-1, and II-2, whereas it is C in II-3, the healthy family member.

been described by McClatchey et al (17).

SCN4A has 4 similar domains (D I-D IV) connected by cytoplasmic loops, each consisting of 6 transmembrane segments (S1-S6) (Fig. 5) (1-8, 37-45). Although the function of each part of domains, cytoplasmic loops, and segments has yet to be fully clarified, the positively charged S4 segments are speculated to function as voltage sensors for channel activation $(1-8,37-45)$. In addition, the pore $(\mathrm{P})$ region located between S5 and S6 in each domain is considered important for ion permeability (37), and the intracellular loop between D III and D IV is thought to have key importance in the rapid inactivation of this channel (37-39). Furthermore, voltage-clamp studies of single fibers from PMC patients have shown that sodium current inactivation is incomplete (40). Defective inactivation with increased sodium influx results in the depolarization of muscle fibers

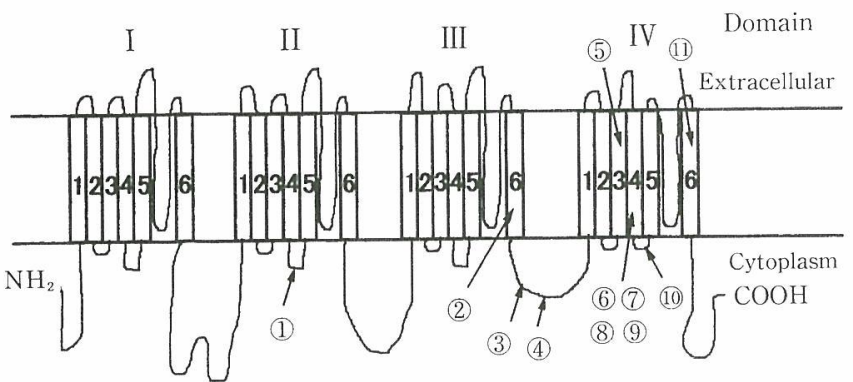
(1) Ile693Thr
(5) Leu1433Arg
(9) Gly $1456 \mathrm{Glu}$
(2) Val1293Ile
(6) $\operatorname{Arg} 1448 \mathrm{Cys}$
(10) Phel473Ser
(3) Gly $1306 \mathrm{Val}$
(7) $\operatorname{Arg} 1448 \mathrm{His}$
(11) Val1589Met
(4) Thr1313Met
(8) Arg1448Pro

Figure 5. Diagram showing the adult skeletal muscle sodium channel $\alpha$-subunit. Each domain (D I-D IV) has 6 transmembrane segments (S1-S6). Eleven mutations, including the one in our family (4), have been identified in paramyotonia congenita (PMC). Mutations associated with this disease are concentrated in both D IV and the cytoplasmic loop between D III and D IV.

(40). Patch-clamp studies of human muscle cell lines obtained from patients with PMC, Hyper PP, or potassiumaggravated myotonia have clarified the pathophysiological mechanisms of these diseases and show the importance of the protein parts as channel function sites $(41-45)$. The degree of depolarization therefore determines the clinical phenotype. Slight depolarization causes membrane hyperexcitability and muscle stiffness, whereas substantial, sustained depolarization induces membrane inexcitability and muscle paralysis. Substitution of the amino acid (Thr1313Met) located in the cytoplasmic loop between D III and IV may cause the defective inactivation that results in myotonia and/or muscle stiffness. In contrast, temperature dependence of the mutant sodium channel has been documented in four studies (17-20). Ion channel mutations that result in temperature-sensitive behavior have been reported for sodium channels in Drosophila and chloride channels in humans (46, 47). Sustained current induced by one mutation in the SCN4A gene of PMC patients increased as temperature decreased (19). In other studies $(17,18,20)$, in PMC with Thr1313Met the mean channel open time was similar to that of the controls at $32^{\circ} \mathrm{C}$ but prolonged at $22^{\circ} \mathrm{C}$. In PMC, a temperature-dependent abnormality in the mutant sodium channel therefore causes cold-induced myotonia and/or muscle stiffness.

In comparison to Caucasians, such hereditary sodium channelopathies as PMC, Hyper PP, Hypo PP type 2, and potassium-aggravated myotonia are relatively rare in Asian peoples, including the Japanese. It is not clear whether the prevalence of these diseases is related to differences in race, one reason for which is the lack of genetic diagnoses. In Japan, few laboratories are able to detect missense mutations in the SCN4A gene. Mexiletine, however, prevents attacks of cold-provoked myotonia and/or muscle stiffness in patients 
with PMC, and the symptoms seen in our affected family members disappeared rapidly when this drug was used. As a result, patient I-1 is able to attend to her business, and both patients II-1 and II-2 have normal school lives. Because it is one of the few neuromuscular diseases in which drug treatment is able to control symptoms, PMC in Japan needs to be investigated more widely and in depth in order to increase the quality of PMC patients' lives.

\section{Conclusion}

A Japanese woman, one of her sons, and her daughter have suffered cold-induced myotonia and muscle stiffness from early childhood. DNA analyses of these patients' SCN4A genes detected a $\mathrm{C}$ to $\mathrm{T}$ transition at nucleotide position 3938 in exon 22 (Thr1313Met) in all three. PMC, of very low prevalence in Japan, was diagnosed from the patients' clinical features and DNA analysis findings.

\section{References}

1) Hoffman EP, Lehmann-Horn F, Rüdel R. Overexcited or inactive: ion channels in muscle disease. Cell 80: 681-686, 1995.

2) Ashcroft FM. Voltage-gated $\mathrm{Na}^{+}$channel. in: Ion Channels and Disease. Ashcroft FM, Ed. Academic Press, San Diego, CA, 2000: 6789.

3) Victor M, Ropper AH. The hereditary myotonias and periodic paralysis. in: Adams and Victor's Principles of Neurology. Victor M, Ropper AH, Eds. McGraw-Hill, New York, 2001: 1553-1560.

4) Hudson AJ, Ebers GC, Bulman DE. The skeletal muscle sodium and chloride channel diseases. Brain 118: 547-563, 1995.

5) Cannon SC. Voltage-gated ion channelopathies of the nervous system. Clin Neurosci Res 57: 772-779, 2001.

6) Lehmann-Horn F, Jurkat-Rott K. Voltage-gated ion channels and hereditary disease. Physiol Rev 79: 1317-1372, 1999.

7) Becker PE. Myotonia congenita and symptoms associated with myotonia. in: Topics in Human Genetics, Vol. 3, Becker PE, Lenz W, Vogel F, Wendt GG. Eds. George Thieme Verlag, Stuttgart, 1977: 760.

8) Wang J, Dubowitz V, Lehmann-Horn F, et al. In vivo structure/function studies: consecutive Arg1448 changes to Cys, His, and Pro at the extracellular surface of IV S4. in: Ion Channels and Genetic Disease. Dawson DC, Frizzell RA, Eds, Rockefeller University Press, New York, 1995: 77-88.

9) Ptácek LJ, George AL Jr, Barchi RL, et al. Mutations in an S4 segment of the adult skeletal muscle sodium channel cause paramyotonia congenita. Neuron 8: 891-897, 1992.

10) Ptácek LJ, Trimmer JS, Agnew WS, Roberts JW, Petajan JH, Leppert M. Paramyotonia congenita and hyperkalemic periodic paralysis map to the same sodium channel gene locus. Am J Hum Mol Genet 49: 851-854, 1991.

11) Plassart E, Eymard B, Maurs L, et al. Paramyotonia congenita: genotype to phenotype correlations in two families and report of a new mutation in the sodium channel gene. J Neurol Sci 142: 126-133, 1996.

12) Koch MC, Baumbach K, George AL, Ricker K. Paramyotonia congenita without paralysis on exposure to cold: a novel mutation in the SCN4A gene. Neuroreport 6: 2001-2004, 1995.

13) Sasaki R, Takano H, Kamakura K, et al. A novel mutation in the gene for the adult skeletal muscle sodium channel $\alpha$-subunit (SCN4A) that causes paramyotonia congenita of von Eulenburg. Arch Neurol 56: 692-696, 1999.

14) Davies NP, Eunson LH, Gregory RP, Mills KR, Morrison PJ, Hanna MG. Clinical, electrophysiological, and molecular genetic studies in a new family with paramyotonia congenita. J Neurol Neurosurg Psychiatry 68: 504-507, 2000.

15) Borg K, Ahlberg G, Anvret M. C4342T-mutation in the SCN4A gene on chromosome 17q in a Swedish family with paramyotonia congenita (Eulenburg) - correlations with clinical, neurophysiological and muscle biopsy data. Neuromuscul Disord 7: 231-233, 1997.

16) Ochi H, Yamada T, Hara H, Yoshimura T, Kobayashi T. A Japanese family with paramyotonia congenita which has a mutation in the muscle sodium channel gene. Rinsho Shinkeigaku (Clinical Neurol) 35: 893-896, 1995 (in Japanese, Abstract in English).

17) McClatchey AI, Van den Bergh P, Pericak-Vance M, et al. Temperature-sensitive mutations in the III-IV cytoplasmic loop region of the skeletal muscle sodium channel gene in paramyotonia congenita. Cell 68: 769-774, 1992.

18) Boulos PT, Heiman-Patterson TD, Alexander GM, Tahmoush AJ. Patch clamp studies of the Thr1313Met mutant sodium channel causing paramyotonia congenita. Muscle Nerve 23: 1736-1747, 2000.

19) Fleischhauer R, Mitrovic N, Deymeer F, Lehmann-Horn F, Lerche H. Effects of temperature and mexiletine on the F1473S Na${ }^{+}$channel mutation causing paramyotonia congenita. Pflügers Arch 436: 757-765, 1998.

20) Tahmoush AJ, Schaller KL, Zhang P, Hyslop T, Heiman-Patterson T, Caldwell JH. Muscle sodium channel inactivation defect in paramyotonia congenita with thr1313met mutation. Neuromusc Disord 4: 447-454, 1994.

21) Ptácek LJ, Gouw L, Kwiecinski H, et al. Sodium channel mutations in paramyotonia congenita and hyperkalemic periodic paralysis. Ann Neurol 33: 300-307, 1993.

22) Okuda S, Kanda F, Nishimoto K, Sasaki R, Chihara K. Hyperkalemic periodic paralysis and paramyotonia congenita: A novel sodium channel mutation. J Neurol 248: 1003-1004, 2001.

23) Wagner S, Lerche H, Mitrovic N, Heine R, George AL, Lehmann-Horn F. A novel sodium channel mutation causing a hyperkalemic paralytic and paramyotonic syndrome with variable clinical expressivity. Neurology 49: 1018-1025, 1997.

24) Bulman DE, Scoggan KA, van Oene MD, et al. A novel sodium channel mutation in a family with hyperkalemic periodic paralysis. Neurology 53: 1932-1936, 1999.

25) Rojas CV, Wang JZ, Schwartz LS, et al. A Met-to-Val mutation in the skeletal muscle $\mathrm{Na}^{+}$channel alpha-subunit in hyperkalemic periodic paralysis. Nature 354: 387-389, 1991.

26) Fontaine B, Khurana ST, Hoffman PE, et al. Hyperkalemic periodic paralysis and the adult muscle sodium channel alpha-subunit gene. Science 250: 1000-1002, 1990.

27) Heine R, Pika U, Lehmann-Horn F. A novel SCN4A mutation causing myotonia aggravated by cold and potassium. Hum Mol Genet 2: 13491353, 1993.

28) Jurkat-Rott K, Mitrovic N, Hang C, et al. Voltage-sensor sodium channel mutations cause hypokalemic periodic paralysis type 2 by enhanced inactivation and reduced current. Proc Natl Acad Sci USA 97: 95499554, 2000.

29) Ricker K, Moxley III RT, Heine R, Lehmann-Horn F. Myotonia fluctuans: a third type of muscle sodium channel disease. Arch Neurol 51: 1095-1102, 1994.

30) Lerche H, Heine R, Pika U, et al. Human sodium channel myotonia: slowed channel inactivation due to substitutions for a glycine within the III-IV linker. J Physiol 470: 13-22, 1993.

31) Ptácek LJ, Tawil R, Griggs RC, et al. Sodium channel mutations in acetazolamide-responsive myotonia congenita, paramyotonia congenita, and hyperkalemic periodic paralysis. Neurology 44: 1500-1503, 1994.

32) Koch MC, Steinmeyer K, Lorenz C, et al. The skeletal muscle chloride channel in dominant and recessive human myotonia. Science 257: 797800, 1992.

33) Becker PE. Generalized non-dystrophic myotonica, The dominant (Thomsen) type and the recently identified recessive type. in: New developments in Electromyography and Clinical Neurophysiology, Vol. 


\section{Paramyotonia Congenita}

1, Desmedt JE, Ed. Karger, Basel, 1973: 407-412.

34) Moxley III RT. Channelopathies. Curr Treat Options Neurol 2: 31-47, 2000.

35) Witt TN, Lane RJM. Myotonias. in: Neurological Disorders. Course and Treatment, Brandt T, Caplan LR, Dichgans J, Diener HC, Kennard C, Eds. Academic Press, San Diego, CA, 1996: 997-1002.

36) Fan Z, George AL, Kyle JW, Makielski JC. Two human paramyotonia congenita mutations have opposite effects on lidocaine block of $\mathrm{Na}^{+}$ channels expressed in a mammalian cell line. J Physiol 496: 275-286, 1996.

37) Heinemann SH, Terlau H, Stühmer W, Imoto K, Numa S. Calcium channel characteristics conferred on the sodium channel by single mutations. Nature 356: 441-443, 1992.

38) West JW, Patton DE, Scheuer T, Wang Y, Goldin AL, Catterall WA. A cluster of hydrophobic amino acid residues required for fast $\mathrm{Na}^{+}$ channel inactivation. Proc Natl Acad Sci USA 89: 10910-10914, 1992.

39) Ragsdale DS, McPhee JC, Scheuer T, Catterall WA. Molecular determinants of state-dependent block of $\mathrm{Na}^{+}$channels by local anesthetics. Science 265: 1724-1728, 1994.

40) Lehmann-Horn F, Rüdel R, Ricker K. Membrane defects in paramyotonia congenita (Eulenburg). Muscle Nerve 10: 633-641, 1987.
41) Cannon SC, Strittmatter SM. Functional expression of $\mathrm{Na}^{+}$channel mutations identified in families with periodic paralysis. Neuron 10: $317-$ 326, 1993.

42) Cummns TR, Zhou J, Sigworth FJ, et al. Functional consequence of a $\mathrm{Na}^{+}$channel mutation causing hyperkalemic periodic paralysis. Neuron 10: 667-678, 1993.

43) Chahine M, George AL, Zhou M, et al. Sodium channel mutations in paramyotonia congenita uncouple inactivation from activation. Neuron 12: 281-294, 1994.

44) Mitrovic N, George AL, Heine R, et al. $\mathrm{K}^{+}$-aggravated myotonia: destabilization of inactivated state of the human muscle $\mathrm{Na}^{+}$channel by the V1589M mutation. J Physiol 478 Pt 3: 395-402, 1994.

45) Mitrovic N, George AL, Lerche H, Wagner S, Fahlke C, LehmannHorn F. Different effects on gating of three myotonia-causing mutations in the inactivation gate of the human muscle sodium channel. J Physiol 487: 107-114, 1995.

46) Loughney K, Kreber R, Ganetzky B. Molecular analysis of the para locus, a sodium channel gene in Drosophila. Cell 58: 1143-1154, 1989.

47) Li C, Ramjeesingh M, Reyes E, et al. The cystic fibrosis mutation ( $\triangle \mathrm{F} 508$ ) does not influence the chloride channel activity of CFTR. Nat Genet 3: 311-316, 1993. 